\title{
Understanding the indoor soundscape of study areas in terms of users' satisfaction, coping methods and perceptual dimensions
}

\author{
Volkan Acun ${ }^{\text {a) }}$ and Semiha Yilmazer ${ }^{\text {b) }}$ \\ (Received: 13 June 2017; Revised: 8 February 2018; Accepted: 9 February 2018)
}

\begin{abstract}
The soundscape approach is not concerned with the sound level of an acoustic environment, but how it relates to human perception, how it is conceived by the individual and how it should be measured and managed. Even though it reached wide popularity in the last 15 years, it still lacks standardization. Perceptual dimensions of the indoor soundscape have major contributions to the experience of place. Identifying the relations between the sound and build environment can provide valuable information for the decision-makers to promote sensation, satisfaction and positive emotions. This research focuses on the sound environments of 4 open study areas within the Bilkent University Campus. These spaces have been favored by many students due to their ability to combine learning and social identity, in an informal but also an academic environment. This informality also resulted in with the lack of controlled sound environment which can be found in the silent study zone of the library. For this reason, this article examines the soundscape of the open study areas in terms of sound sources, users' reactions, coping methods and perceptual dimensions. Research settings are located at the dormitories, the Fine Arts Building, the library, and the Faculty of Science Building. In order to explore users' response to the sound environment, a questionnaire survey and in-situ measurement of sound levels (LAeq) have been conducted with 120 students. The questionnaire survey consisted of two main parts which were concerned with identifying sound source, satisfaction, loudness and exploring the perceptual dimensions of the indoor soundscape through semantic differential scales. Results showed no difference between participants' satisfaction with the soundscape regardless of the sound levels. Perceptual dimensions of the indoor soundscape are analyzed with factor analysis which extracted three factors, sensation, activity/communication, and functionality. (C) 2018 Institute of Noise Control Engineering.
\end{abstract}

Primary subject classification: 56.3; Secondary subject classification: 51

\section{INTRODUCTION}

In recent years, open study areas have started to overshadow the strict learning areas of the library. These spaces are especially popular among the undergraduate students as students take command of their own, and combine academic work with social activities ${ }^{1-3}$. Social functions

a) Bilkent University, Faculty of Art, Design and Architecture, Department of Interior Architecture and Environmental Design, Bilkent, Ankara, 06800, TURKEY; email: volkan. acun@bilkent.edu.tr.

b) Bilkent University, Faculty of Art, Design and Architecture, Department of Interior Architecture and Environmental Design, Bilkent, Ankara, 06800, TURKEY; email: semiha@ bilkent.edu.tr. are added to these areas through providing easy access to cafes, art galleries, and multimedia areas which promotes an environment that is open to conversation and cooperative work. Due to this, they are favored among collaborative study groups but also used for individual study. However, because of their informal nature, they are prone to issues with the sound environment, unlike a silent study zone of a library.

While studying in a silent zone, sound levels can cause annoyance, disturbance and frustration ${ }^{4-7}$. However, Bryant et al. observed that, in open study areas, students can adapt to the sound level even if it is high ${ }^{3}$. Harrop and Turpin stated that the sound levels provide a positive contribution to the social aspect of the open study areas ${ }^{5}$. This positive contribution to the social aspect is not only due to the sound levels but perhaps more related with the 
context of the sound. The further evaluation of this sound environment should be conducted with emphasis on the way it is perceived by individuals.

According to the ISO 12913-1, soundscape is defined as "the acoustic environment perceived or experienced and/or understood by a person or people, in context $t^{8}$." This approach started to gain major attention during the last decade, but it was first introduced by Schafer in late 1960 's ${ }^{9}$. Schafer's studies created a new way to evaluate the quality of the sound environment. He used both negative and positive sound elements to capture the complexity of the sound environment ${ }^{9,10}$. Following up on Schafer's work, research conducted by various scholars showed that it is not always the sound levels that matter, but also the information provided by the sound environment and the way it is understood by the individuals ${ }^{11-17}$.

Even though the definition and conceptual framework of the soundscape are identified by the ISO 12931-1, the evaluation methods are still controversial. The rules and regulations associated with the sound environments are mostly concerned with sound levels (SPL) but not with the way it is experienced by the individuals. In 2002, European Noise Directive required adjusting sound levels according to the predetermined values and maintaining quiet zones, but it did not specify any methods ${ }^{18}$. This led many researchers to search for different ways of evaluating the soundscapes. One of the common methods is the binaural recordings of the soundscapes, which are used by authors for laboratory experiments ${ }^{19-21}$. Interviews and questionnaire survey, which are concerned with noise annoyance and perceptual dimensions of soundscape, are very common methods ${ }^{10,22-29}$.

Vast majority of the soundscape studies focused on the urban soundscape and it has been assumed that same methods will apply to the indoors ${ }^{12}$. Brown et al. created a taxonomy of acoustic environment that categorized places and sound sources ${ }^{12}$. In terms of places, the acoustic environment is divided into two main categories as indoor and outdoor, with outdoor acoustic environment having several sub-environments (rural, urban, etc.). Sound sources have numerous subcategories but in general they can be divided into two major types as those generated by human activity and those which are not. In their research, authors stated that interpretation of the same sound source can change from place to place as it is highly influenced by the context.

Qualitative research methods are used in both indoor and outdoor spaces to capture individuals' subjective response to the soundscape. Mackrill et al. used grounded theory to conceptualize the lived in experience of a hospital ward and found that patients are coping with the aspects of soundscape by accepting and habituating to the soundscape ${ }^{29}$. Similarly, Acun and Yilmazer also found that individuals are coping with the negative aspects of the soundscape by using earphones, physically or verbally interfering to the sound source and/or through adaptation ${ }^{30}$.

Individuals' interaction with the acoustic environment is commonly examined by noise annoyance surveys and quantitative measurements. When the psychological aspect of the acoustic environment was considered, a more qualitative approach needs to be considered ${ }^{22}$. As a psychological descriptor, the perceptual dimensions of the soundscape can be used as an evaluation structure ${ }^{23}$. The research carried out by Kang and Zhang ${ }^{31}$ determined the key factors of urban soundscape using semantic differentials technique and extracted four factors: relaxation, communication, spatiality, and dynamics. Cain et al. ${ }^{22}$ used semantic differential scales and identified calmness and vibrancy as principal perceptual dimensions of soundscape that can be used to evaluate how a place makes users feel.

This research focused on four open study areas that are found within the Bilkent University Campus. Until last couple of years, study areas were only located within the library. Recently, study areas were created in various locations in the Bilkent University Campus. Each of these spaces is subject to various sound events. One of the aims of this research is to explore the sound environment of the study areas and compare students' satisfaction with the sound environment, perceived loudness, and overall satisfaction; afterwards, to identify the coping methods employed by the students; and lastly, to explore the perceptual dimensions of the indoor soundscape.

\section{METHOD}

\subsection{Case Study Settings}

The research was conducted at four open study areas in Bilkent University Campus. First case study site is located at the library, site 2 is at the Faculty of Fine Arts Design and Architecture, site 3 is at the Faculty of Science, and site 4 is located at the 77th dormitory (Fig. 1). Each of the case study sites has slight differences. The open study area of site 1 is located at the second floor of the library and it is surrounded with study rooms. Sites 2 and 3 are located at the ground floor of large buildings and they are in an atrium. There is a Starbucks right adjacent to the study area of site 2 . On the other hand, site 3 has a small fountain right in the middle of the atrium which adds water element to the sound environment. Finally, the study area of site 4 is a large area located next to a staircase and it consists of both open and enclosed study areas. In order to use similar types of study areas, all measurements and the survey are conducted only in the open study area.

\subsection{Procedure}

This research combined the usage of in-situ sound level measurements and a questionnaire survey. The overall 


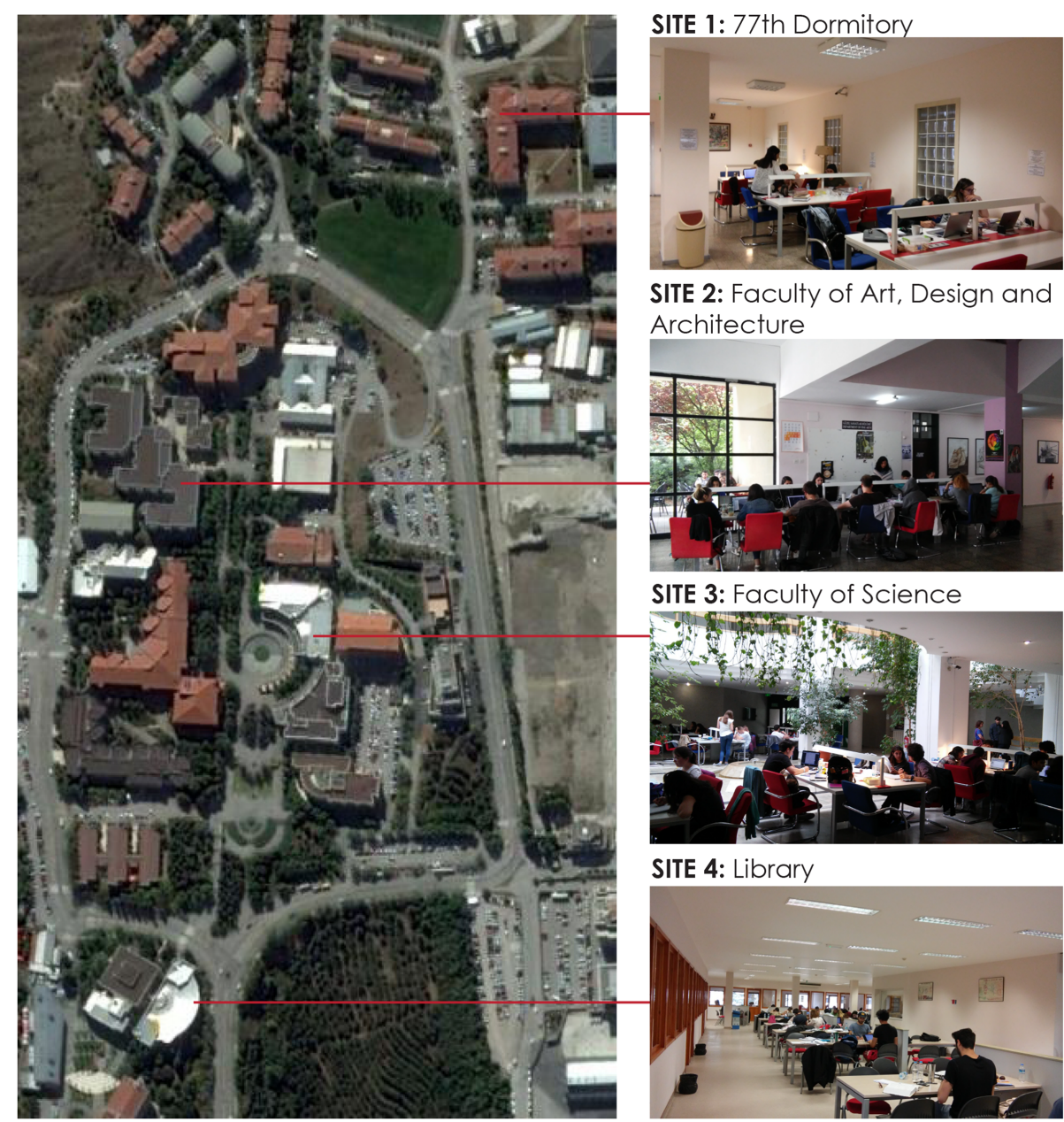

Fig. 1-Case study settings and their locations in the Bilkent University Central Campus.

sound level (LAeq) of each study area is measured to provide a brief information about the sound levels. Bruel \& Kjaer Sound Level Meter type 2230 was used to measure the sound levels. Sound level meter was placed at the height of $125 \mathrm{~cm}$. Measurements are conducted simultaneously with the questionnaire survey. Each measurement is conducted over 15-minute time interval. After 15 minutes, the measurement equipment is moved to a predetermined location within the space. Number of measurement locations differed based on the size and shape of each study area.

Questionnaire survey was conducted with 30 randomly selected students from each study area, with a total of 120 students. The age of the sample group ranged from 18 to $26,45 \%$ being male and 55\% female. All the participants were chosen among those who were studying and those that were performing unrelated activities were avoided. Vast majority of the participants were undergraduate students (95\%).

The questionnaire consisted of three parts. First part of the questionnaire starts with an explanation about the scope of the study, how the collected data will be stored, for what purposes it will be used, and the demographic information about the participant, as it is required by the ethical committee of the institution. The demographic information consisted of age, gender, grade, frequency of visiting the study area, and the duration of the visit. The second part of the questionnaire used 5-point Likert scales to evaluate students' satisfaction with the sound environment, perceived loudness of the sound environment and the overall satisfaction with the study area. Participants responded to the statements (1-Strongly Disagree, 5-Strongly Agree) such as "I am satisfied with this study area in general" and "This sound environment is not loud." These were followed by questions regarding the sound sources, which were identified by pilot study. Participants were asked to rank the given sound sources based on how frequently they hear them $(1=$ Very rarely, $5=$ Constantly $)$ and based on how disturbing they are $(1=$ Very disturbing, $5=$ Not disturbing at all). This part of the questionnaire concluded with asking participants how they cope with unsatisfactory sound environment.

Third and the last part of the questionnaire aimed to explore the perceptual dimensions of the soundscape. This part used semantic differential scale method which consisted of 14 adjective pairs (Table 1). Adjective pairs 
Table 1-List of adjective pairs used at the survey.

\begin{tabular}{llllllllc}
\hline \hline Discomfort & 1 & 2 & 3 & 4 & 5 & 6 & 7 & Comfort \\
Unpleasant & 1 & 2 & 3 & 4 & 5 & 6 & 7 & Pleasant \\
Slow & 1 & 2 & 3 & 4 & 5 & 6 & 7 & Fast \\
Soft & $\mathbf{1}$ & $\mathbf{2}$ & $\mathbf{3}$ & $\mathbf{4}$ & $\mathbf{5}$ & $\mathbf{6}$ & $\mathbf{7}$ & Hard \\
Boring & 1 & 2 & 3 & 4 & 5 & 6 & 7 & Interesting \\
Unbearable & 1 & 2 & 3 & 4 & 5 & 6 & 7 & Bearable \\
Discontinuous & 1 & 2 & 3 & 4 & 5 & 6 & 7 & Continuous \\
Noisy & 1 & 2 & 3 & 4 & 5 & 6 & 7 & Quiet \\
Unsocial & 1 & 2 & 3 & 4 & 5 & 6 & 7 & Social \\
Static & 1 & 2 & 3 & 4 & 5 & 6 & 7 & Dynamic \\
Rough & $\mathbf{1}$ & $\mathbf{2}$ & $\mathbf{3}$ & $\mathbf{4}$ & $\mathbf{5}$ & $\mathbf{6}$ & $\mathbf{7}$ & Smooth \\
Nearby & 1 & 2 & 3 & 4 & 5 & 6 & 7 & Far \\
Annoying & 1 & 2 & 3 & 4 & 5 & 6 & 7 & Not annoying \\
Repulsive & 1 & 2 & 3 & 4 & 5 & 6 & 7 & Inviting \\
\hline \hline
\end{tabular}

Bold pairs were eliminated during statistical analyses.

were ranked using a 7-point scale. In order to choose the adjective pairs, previous studies and the characteristics of the case study settings were considered ${ }^{10,17,21-23,31}$. After the examination of questionnaire results, two of the adjective pairs, soft-hard and rough-smooth, were eliminated. These adjective pairs were not clearly understood by a portion of the students as they had difficulties relating them with the sound environment. Thus, the two pairs were removed from the data set during analysis, to avoid any potential bias. After the data collection is completed, it is statistically analyzed with IBM SPSS Statistics 21 .

\section{RESULTS}

\subsection{The Sound Environment}

Sound level measurements (LAeq) showed that there is a great difference between four study areas. The LAeq measurements for the case study settings are as follows: $62.2 \mathrm{~dB}(\mathrm{~A})$ for site $1,57.2 \mathrm{~dB}(\mathrm{~A})$ for site $2,55.7 \mathrm{~dB}(\mathrm{~A})$ for SA site 3 and $47.2 \mathrm{~dB}(\mathrm{~A})$ for site 4 . These measurements showed that there is $14 \mathrm{~dB}(\mathrm{~A})$ sound level different between the loudest (site 1) and the quietest (site 4) study areas $^{6}$

Reliability of the questionnaire was tested with Cronbach's $\alpha^{32}$, which provided a score of 0.706 for the second part. According to the results, $57.5 \%$ of the participants are satisfied or very satisfied with their study environment while $24.2 \%$ is neutral and only $18.3 \%$ are unsatisfied or very unsatisfied. However, a total of $28.3 \%$ of the participants expressed that they are dissatisfied and $10 \%$ expressed that they are very dissatisfied with the sound environment (Fig. 2). When participants were asked to respond "This sound environment is not loud," $47.5 \%$ of the participants disagreed with the statement (Fig. 3), which shows that they actually think it is loud.
Sound environment

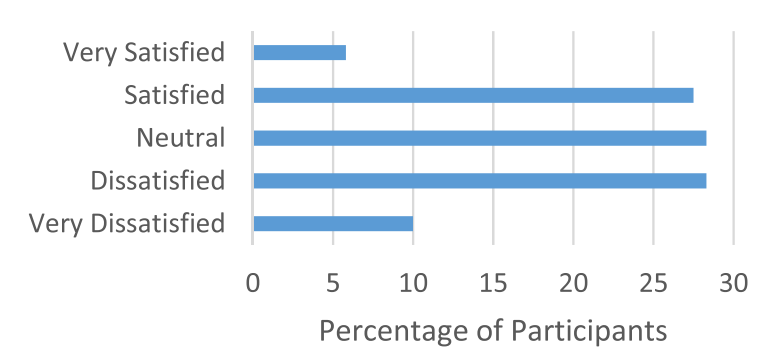

\section{Fig. 2-Students' satisfaction with the sound environment.}

To compare the amount of perceived loudness of the study areas, ANOVA F-test is used ${ }^{33}$ (Table 2). Results revealed no statistically significant difference between the study areas in terms of perceived loudness $(F(3,116)=$ $2.681, p=0.052=p>0.05)$. Similarly, no statistically significant difference has been found among the study areas regarding the satisfaction with the soundscape $(F(3,116)=$ $2.412, p=0.074, p>0.05)$. The lack of difference between these study areas, in terms of satisfaction and perceived loudness, is an interesting finding as there is almost $14 \mathrm{~dB}(\mathrm{~A})$ difference between the quietest (site 4) and the loudest (site 1) study area.

ANOVA F-test was also used to compare students' selfrated satisfaction with the study areas. However, Levene's test for equality of variances was found to be violated for this variable $(F(3,116)=2.818, p=0.042)$. This suggested that the population variance was unequal ${ }^{32}$. With this regard, we analyzed students' self-rated satisfaction by using the non-parametric Kruskal-Wallis H-test ${ }^{32}$ (Table 2). Statistical analysis indicated that there is a statistically significant difference between the study areas in terms of overall satisfaction $\left(\chi^{2}(3)=8.133, p=0.043\right)$. Tamhane's T2 post hoc test suggests that significant differences in overall satisfaction were obtained between site 1 and site $4(p=0.023)$.

\subsection{Sound Sources}

During preliminary study, we have asked the students to list all the sound sources they can hear. Their responses are grouped under nine titles. Ambiguous sound sources are

This sound environment is not loud

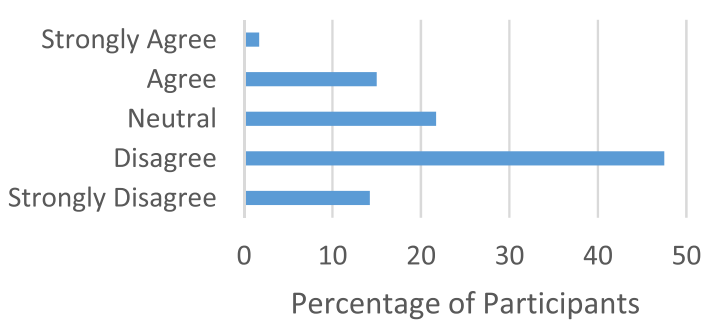

Fig. 3-Students' response to the question of "This sound environment is not loud." 
Table 2-Results of the one-way ANOVA F-test, Kruskal-Wallis H-test and the homogeneity of variance.

\begin{tabular}{|c|c|c|c|c|c|c|c|c|c|c|}
\hline & \multicolumn{2}{|c|}{$\begin{array}{c}\text { Homogenity of } \\
\text { variance }\end{array}$} & \multicolumn{5}{|c|}{$\begin{array}{c}\text { One-way ANOVA } \\
\text { F-test }\end{array}$} & \multicolumn{3}{|c|}{$\begin{array}{c}\text { Kruskal-Wallis } \\
\text { H-test }\end{array}$} \\
\hline & $\begin{array}{l}\text { Levene } \\
\text { statistic }\end{array}$ & $p$ & $\begin{array}{l}\text { Sum of } \\
\text { squares }\end{array}$ & $\begin{array}{l}\text { Mean } \\
\text { square }\end{array}$ & $d f$ & $F$ & $p$ & $d f$ & $X^{2}$ & $p$ \\
\hline Satisfaction with the soundscape & 0.196 & 0.899 & 8.355 & 2.785 & 3 & 2.412 & 0.074 & - & - & - \\
\hline Percieved loudness & 1.580 & 0.198 & 7.219 & 2.406 & 3 & 2.681 & 0.051 & - & - & - \\
\hline Satisfaction with the environment & 2.818 & 0.042 & - & - & - & - & - & 3 & 8.133 & 0.043 \\
\hline
\end{tabular}

grouped together and listed under the same title (e.g., sounds caused by doors, chairs, or the building equipment are grouped and listed under environmental sounds). The nine sound sources that are listed are intelligible speech, unintelligible speech, laughing, footsteps, ventilation, water sound, music, computer sound (keyboard, mouse, fan), and environmental sounds (door, chair, etc.).

Students are asked to rank how frequently they hear each sound sources based on a scale from "1-Very rarely" to "5-Constantly". Analysis of the questionnaires revealed that human-generated sounds are the most frequently heard ones (Fig. 4). Among these, unintelligible speech is the most frequently heard sound, with $32 \%$ of the participants stating that they heard it constantly. It is followed very closely by intelligible speech (30\%) and laughing sound (29.2\%). Water sound (74.2\%) and ventilation $(63.3 \%)$ sound are the least heard sounds, with a vast majority of the participants saying that they heard them very rarely. Water sound is by far the most rarely heard sound. This is due to the fact that it is exclusive to the SA Building which will be discussed further in the discussion chapter.

When we examine the sound sources based on disturbance, intelligible speech is the most disturbing sound with $20 \%$ of the students ranking it as very disturbing and $43.4 \%$ as disturbing (Fig. 5). Laughing sound is also very close to intelligible speech, with $15.8 \%$ of the students stating that it is very disturbing and $45.8 \%$ disturbing. Unintelligible speech is found to be less disturbing than the intelligible speech which is consistent with the literature ${ }^{34}$.

In order to explore the association between students' self-rated satisfaction with the sound environment, perceived loudness and sound sources, a Spearman's $\rho$ correlation test is applied. This test showed statistically significant relation for 7 items (Table 3). Moderate positive association is observed between the satisfaction with the sound environment and perceived loudness. To properly interpret this result, we need to consider that the Likert scales for satisfaction are " 1 = very dissatisfied and $5=$ very satisfied," and Likert scales for loudness are " 1 = strongly disagree, $5=$ strongly agree." This indicates that satisfaction increases as the sound environment is less loud $(r(120)=0.540, p<0.01)$.

The examination of correlation for sound sources showed that the strongest correlation is observed for the laughing sounds (Table 3 ). There is a moderate positive association between the disturbance caused by the

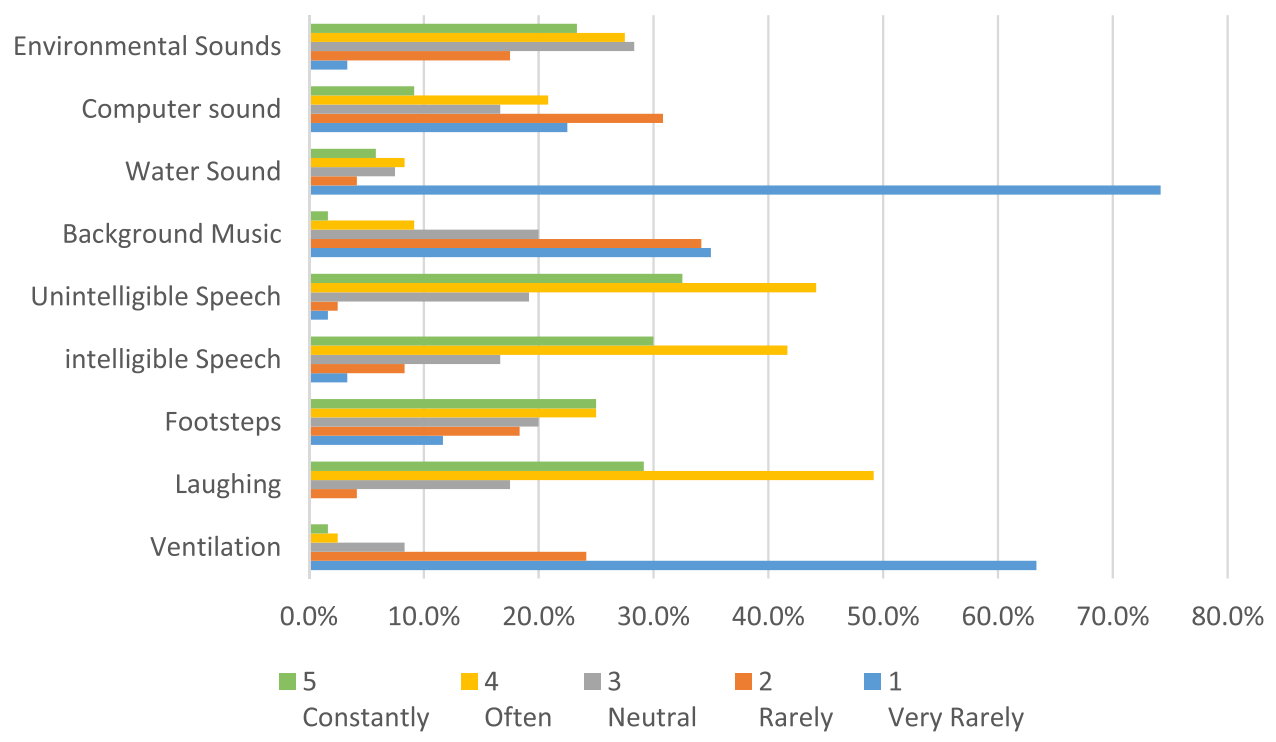

Fig. 4-Frequency of perception of the sound sources for all four study areas. 


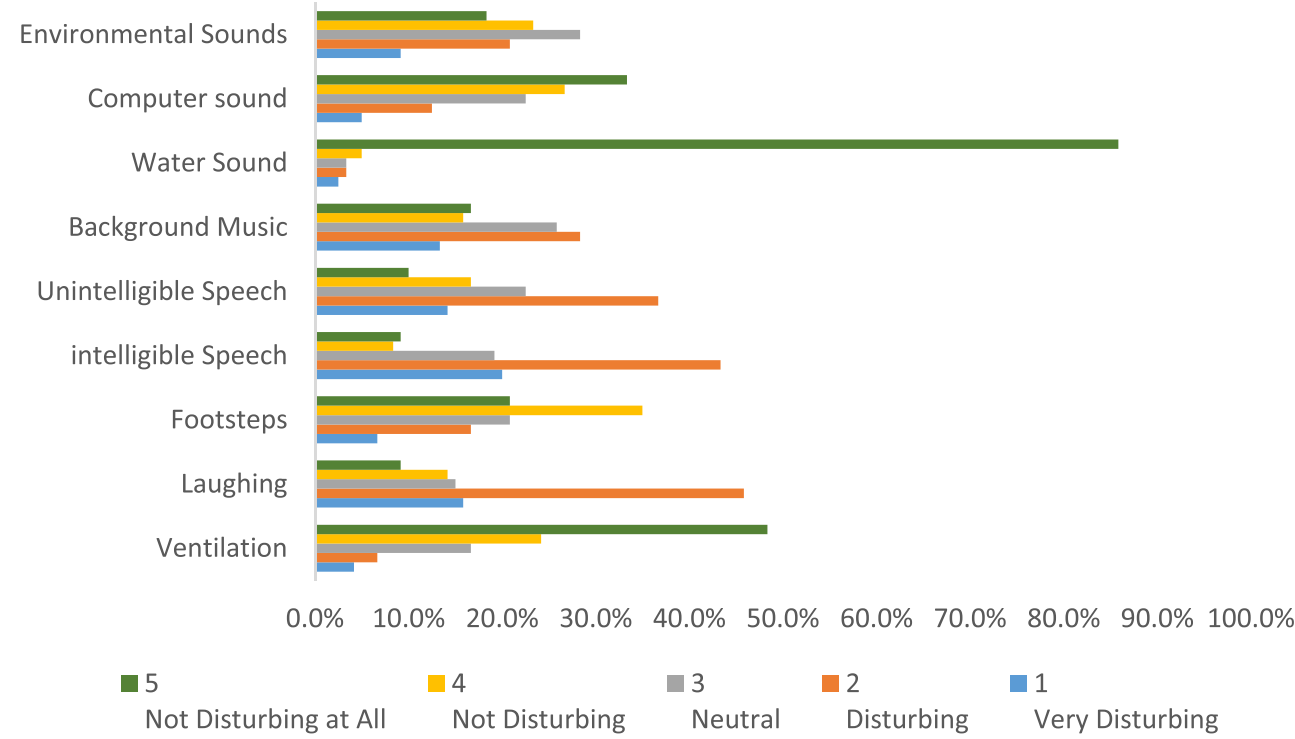

Fig. 5-Disturbance caused the sound sources.

sound of laughing and satisfaction with the sound environment $(r(120)=0.511, p<0.01)$. This shows that the students were more satisfied with the sound environment (1-Very dissatisfied, 5-Very satisfied) as they were less disturbed by laughing sounds (1-Very disturbing, 5Not disturbing at all). Laughing is very closely followed by the unintelligible speech $(r(120)=0.502, p<0.01)$ and intelligible speech $(r(120)=0.471, p<0.01)$, with both having moderate positive association. No significant relation has been observed for background music, ventilation and water sounds.

Participants are also asked to respond to the statement of "Sound environment of this study area does not disturb my concentration" from " 1 = Strongly disagree" to " 5 = Strongly agree." Response to this statement is

\section{Table 3-Spearman's $\rho$ correlation coefficients for disturbance caused by sound sources (significance, $* p<0.05, * * p<0.01$ ).}

\begin{tabular}{lcc}
\hline \hline & $\begin{array}{c}\text { Satisfaction } \\
\text { with the } \\
\text { sound } \\
\text { environment }\end{array}$ & $\begin{array}{c}\text { Self-rated } \\
\text { concentration }\end{array}$ \\
\hline Loudness & $-0.540^{* *}$ & $0.472^{* *}$ \\
Ventilation & -0.027 & 0.051 \\
Laughing & $0.511^{* *}$ & $0.531^{* *}$ \\
Footsteps & $0.250^{* *}$ & $0.357 * *$ \\
Intelligible speech & $0.471^{* *}$ & $0.529 * *$ \\
Unintelligible speech & $0.502 * *$ & $0.538^{* *}$ \\
Background music & 0.076 & 0.177 \\
Water sound & 0.067 & 0.093 \\
Computer sound & $0.192^{*}$ & $0.308^{* *}$ \\
Environmental sounds & $0.237 * *$ & $0.279 * *$ \\
\hline \hline
\end{tabular}

correlated with disturbance caused by each sound source (Table 3). Moderate positive association is observed between the perceived loudness and self-rated concentration $(r(120)=0.472, p<0.01)$. Highest correlations for sound sources are observed for unintelligible speech, laughing sound, and intelligible speech. Among these, unintelligible speech has the highest correlation coefficient $(r(120)=$ $0.538, p<0.01)$ and moderate positive association. This indicates that self-rated concentration increases as participants were less disturbed by the unintelligible speech.

\subsection{Coping Methods}

During the preliminary research, students were asked what they do when they were unsatisfied with the sound environment which ended up generating four coping methods. These methods were putting on earphones (to listen music, etc.), moving to a quieter place, leaving the study area, and interfering with the sound source. In the questionnaire, participants were responded to each action between " $1=$ strongly disagree" and " $5=$ strongly agree."

Figure 6 shows that the majority of the students would put on earphones when they are unsatisfied with the sound environment (39.2\% agree, $29.2 \%$ strongly agree). Another common coping method is relocating to a quieter place within the study area (40\% agree, $12.5 \%$ strongly agree). Leaving the study area is another common method, with $25.8 \%$ agreeing and $13.3 \%$ strongly agreeing. In contrast, interfering with the sound source is absolutely not favored among the participants with $31.7 \%$ strongly disagreeing and 30\% disagreeing.

\subsection{Perceptual Dimensions of the Indoor Soundscape}

The responses to the 12 adjective pairs have undergone factor analysis to extract the core factors that reflect the 


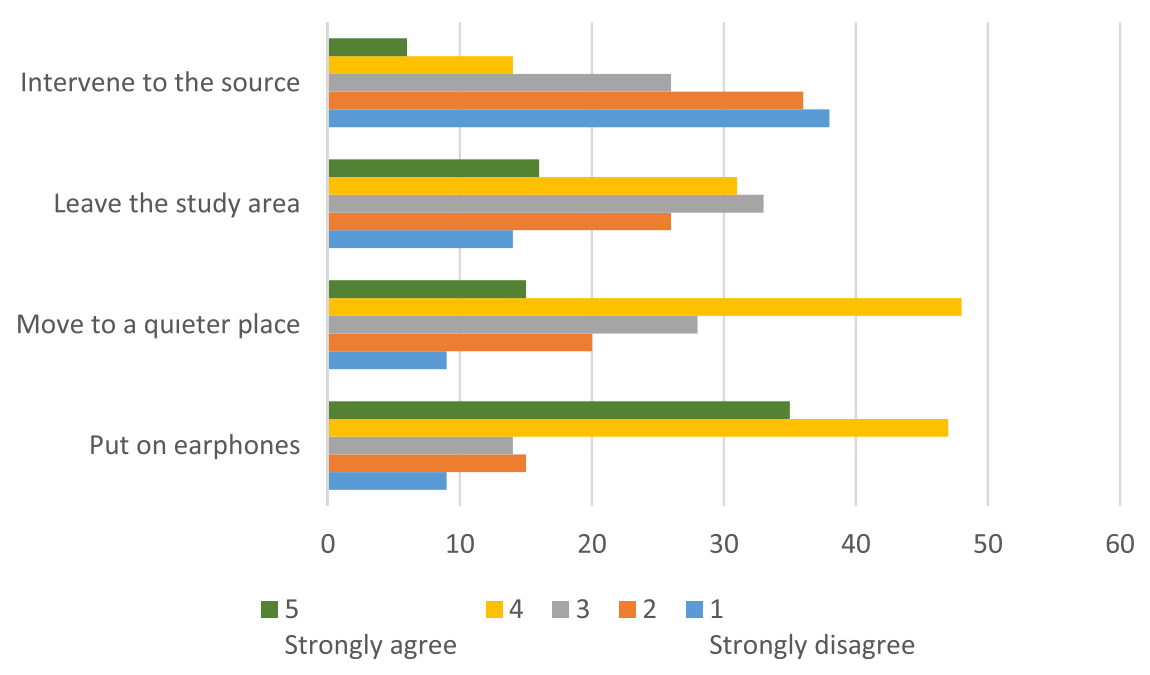

Fig. 6-Coping methods employed by the participants.

perceptual dimensions of the indoor soundscape of the study areas. Before conducting the factor analysis, Cronbach's $\alpha$ reliability test was conducted for the semantic scales, which resulted in an acceptable value of $0.776^{32}$. Factor analysis is conducted using principal components analysis method, with Varimax rotation. Kaiser-Meyer-Olkin measure of sampling adequacy value is calculated as 0.887 , which indicates that the data are adequate for factor analysis ${ }^{35}$.

Factor analysis identified three factors that cover 58.8\% of the total variance (Table 4). Factor 1 accounted for the $34.7 \%$ of the variance. It is consisted of comfort-discomfort, pleasant-unpleasant, interesting-boring, bearable-unbearable, quiet-noisy, annoying-not annoying, and inviting-repulsive, which are associated mainly with sensation. Factor 2 (14.7\%) consisted of only two items: social-unsocial and dynamic-

Table 4-Extracted factors, the factor loadings after rotation and the variance factors cover.

\begin{tabular}{lccc}
\hline \hline Semantic scales & \multicolumn{3}{c}{ Factor } \\
\cline { 2 - 4 } & $\begin{array}{c}1 \\
(34.7 \%)\end{array}$ & $\begin{array}{c}2 \\
(14.7 \%)\end{array}$ & $(9.3 \%)$ \\
\hline Comfort-discomfort & 0.684 & & \\
Pleasant-unpleasant & 0.698 & & \\
Interesting-boring & 0.679 & & \\
Bearable-unbearable & 0.645 & & \\
Continuous-discontinuous & & & \\
Quiet-noisy & 0.609 & & \\
Social-unsocial & & 0.826 & \\
Dynamic-static & & 0.873 & \\
Not annoying-annoying & 0.872 & & \\
Inviting-repulsive & 0.829 & & -0.752 \\
Far-near & & & 0.614 \\
Fast-slow & & & \\
\hline \hline
\end{tabular}

static, which are related with activity/communication. The last factor (9.3\%) included items of far-near and fast-slow. These are mainly associated with functionality.

An examination of the frequency tables of adjective pairs reveals that the results are consistent with the literature (Fig. 7). The study areas are favored as they provide a social and relaxed environment in which they can perform academic work ${ }^{2,3}$. Majority of the students perceive the soundscape of the study areas as social and dynamic. According to the figure, participants also think that the study areas are rather noisy, but they are still satisfied with the indoor soundscape, which shows the importance of context rather than the sound levels alone. It was suggested by Kawai and colleagues that emotional response of the soundscape can be used to create and evaluation structure, which can be applied to real life scenarios ${ }^{23}$.

In order to relate the physical data with students' reactions, Spearman's $\rho$ correlation test is used. The test is conducted between the LAeq measurements, 12 adjective pairs, satisfaction with the sound environment, the perceived loudness, and the satisfaction with the sound environment (Table 5). Nearly all of the correlations coefficients indicate a very weak association between the LAeq measurements and students reactions. Only weak association is observed for the adjective pair of "NearbyFar" $(r(120)=0.308, p<0.01)$.

\section{DISCUSSION}

Throughout the research, four study areas are compared in terms of overall satisfaction, perceived loudness, self-rated satisfaction with the soundscape and the perceptual dimensions of the indoor soundscape are identified. The statistical comparison of perceived loudness and satisfaction with the sound environment showed no difference between study areas, even though there are differences between the spaces in terms of sound levels. 


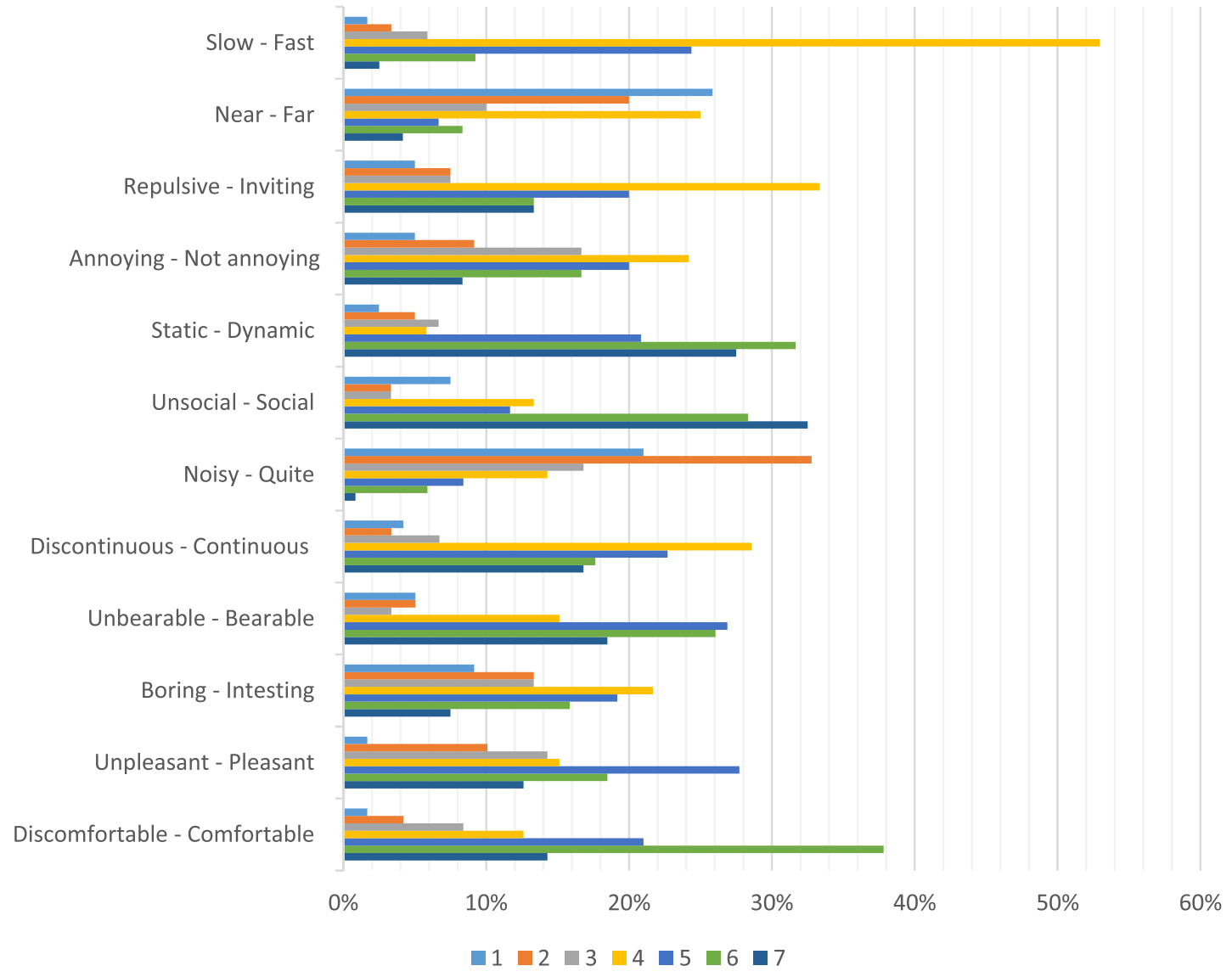

Fig. 7-Frequency chart for semantic differential scales.

Table 5-Spearman's $\rho$ correlation coefficients comparing students' reactions (adjective pairs, satisfaction with the environment, perceived loudness and satisfaction with the sound environment) with the LAeq measurements (significance, ${ }^{*} p<0.05$, $* * p<0.01)$.

\begin{tabular}{lc}
\hline \hline & LAeq \\
\hline Nearby-far & $0.308^{* *}$ \\
Annoying-not annoying & 0.127 \\
Repulsive-inviting & 0.084 \\
Boring-interesting & 0.010 \\
Unbearable-bearable & 0.104 \\
Discontinuous-continuous & -0.101 \\
Noisy-quiet & -0.017 \\
Unsocial-social & 0.118 \\
Static-dynamic & 0.143 \\
Comfortable-discomfortable & 0.077 \\
Unpleasant-pleasant & $0.191^{*}$ \\
Slow-fast & -0.088 \\
Satisfaction with the environment & 0.225 \\
Perceived loudness & -0.083 \\
Satisfaction with the sound environment & $0.206^{*}$ \\
\hline \hline
\end{tabular}

Only difference is observed for the overall satisfaction in two of the study areas.

One of the issues that came up during the research is regarding the fountain in site 3 . This issue presented a possible limitation as the other three study areas did not have a water element. A closer look at site 3 shows that $23.3 \%(n=7 / 30)$ stated that they heard the water sound constantly and $33.3 \%(n=10 / 30)$ often. Regardless of this, according to the ANOVA F-test results, there is no statistically significant difference between site 3 and the other sites in terms of overall satisfaction, perceived loudness and self-rated satisfaction with the sound environment.

An interesting finding is related with the loudest (site 1) and the quietest (site 4) study areas which have an average of $14 \mathrm{~dB}(\mathrm{~A})$ difference in LAeq. Even though a statistical difference is found between these areas, this difference is not associated with the satisfaction with the sound environment or with the perceived loudness but with the overall satisfaction. These findings support those found within the literature. The sound energy alone is not enough to make a judgement about the perception of soundscape $e^{12,13,15,36}$.

The sound sources found in each study are associated with human activities either directly (e.g., speech, laugh) or indirectly (e.g., ventilation, environmental noises). Sounds 
that are generated by non-human activities, such as nature or domesticated animals, and by motorized transports were not present in research sites. Same situation might possibly be the case for other indoor soundscapes such as shopping malls. Some of the negative and positive aspects of urban soundscapes might be absent for indoor soundscapes. The lack of natural sound sources can diminish the restorative potential of soundscapes while the lack of the sound of motorized transport will improve the overall soundscape quality. However, it is not yet clear how well the natural sound sources would fit in with the context of indoor soundscape. There are a variety of different indoor soundscape, each having similarities and differences between one another depending on their functions.

Even though the option of "leaving the study area" is stated as a coping method during the preliminary research, it should not be considered as an actual method of coping with the soundscape. As the setting is an indoor space when you leave the area, you also leave that sound environment. Thus, it is actually abandoning the sound environment rather than coping.

The option of interfering with the sound source can be done in two ways. First one is to verbally interfere with a human generated sound. Study groups are usually the most common human generated source of auditory distraction (e.g., laughing). Students who are annoyed or distracted by sources of this origin can choose express their discomfort to the individuals. Other option is to physically interfering with a non-human sound source, such as the sound of the ventilation system or the coffee machine. One of the reasons why this option is strongly opposed by the participants is that it is not always possible to actually intervene the source. This could either be due to practical or social concerns. Results suggest that both means of interfering with the sound source are less preferred then other coping methods. There is always the possibility that interfering with the sound sources might only fix the problems with the sound environment temporarily. It can be said that, even though students listed 5 different way of coping with an unsatisfactory sound environment, the main study showed that not all of them are practical or even actual coping methods. This only leaves two coping methods, accepting and habituating, and using earphones.

There are some issues regarding using earphones as a coping method. Putting on earphones causes an isolation from the sound environment. It was even expressed by a number of participants (some were written on the questionnaire) that they cannot comment on the soundscape because they hardly ever experience it due to earphones. This issue can provide a possible explanation to the relatively low strength of association between the self-rated concentration and perceived loudness $(r(120)=0.472$, $p<0.01)$. If the sound environment is unsatisfactory, students put on earphones, especially to perform concentration demanding tasks. As they are now isolated from that sound environment, their concentration is not affected as much. Earphones are most commonly used during individual study. In a previous research, it was seen that employees working in open-plan offices were very common using earphones to promote concentration and to cope with annoyance and disturbance caused by isolating themselves from the sound environment ${ }^{30}$. Those participating in a collaborative study group would not use earphones, as it will create a conflict with the purpose of a collaborative study group. It was also indicated by the literature that those in the open study areas do not easily get distracted by loud sound environments with exception of peak sounds ${ }^{3}$.

The total variance covered by the three extracted factors accounts for a relatively low amount of variance (58\%), but similar amounts exist in the literature. Kawai and colleagues found 4 factors that account for $50 \%$ of the variance ${ }^{23}$. The 3 factors identified by Kang and Zhang covered a total amount of $53 \%$ of the variance ${ }^{31}$. A reason for the amount of variance covered by this research might be related with the case study settings. Even though the statistical analysis did not find a statistically significant difference between the study areas in terms of satisfaction with the soundscapes, each study area has different sound environment characteristics. The indoor soundscape of the study area in site 2 is quite similar to that of a coffee shop. On the other hand, soundscape of the site 3 is different as it has a larger volume when compared to the site 1 and site 4 , lacks the coffee shop of the FC building and has its unique water element. As it was commonly expressed by the literature, context is among the key elements of the soundscape approach $^{12,13,29,37}$. Therefore, this difference in context could have caused a difference in the perception of the indoor soundscapes.

\section{SUMMARY AND CONCLUSION}

This study investigated the indoor soundscape of four study areas found within the Bilkent University Campus and examine its perceptual dimensions. Frequency and disturbance caused by the sound sources were identified for each study area. Soundscapes were compared with each other in terms of overall satisfaction, perceived loudness, satisfaction with the sound environment and overall sound levels (LAeq). The effects of disturbance caused by the sound sources towards soundscape satisfaction and concentration were examined through correlations. Finally, semantic differential scales and factor analysis were used to identify participants' the perceptual dimensions of the indoor soundscape.

Even though the measured sound levels of the study area differed, it can be said that this difference was not 
reflected on the soundscape satisfaction. A difference in the satisfaction with the space however, was observed for two study areas. Both the most disturbing and frequently heard sounds were generated by human activities which were, intelligible and unintelligible speech, laughing and walking. These activities were also causing a moderate effect on participants' self-rated concentration. Factor analysis of semantic differential scales extracted 3 perceptual dimensions, which were wellbeing, activity/communication and functionality. Due to the sample size constraints, it was not possible to compare the perceptual dimensions of each space using factor analysis. In further research, larger sample groups can be obtained to compare different indoor soundscapes. As it was also stated by the literature, it may not be desirable to generalize the perceptual dimensions of soundscape as it can be differed based on the function, volume and characteristics of the space.

\section{REFERENCES}

1. S. Bennett, "First questions for designing higher education learning spaces", J. Acad. Librariansh., 33, 14-26,(2007).

2. R. Applegate, "The library is for studying. Student preferences for study space", J. Acad. Librariansh., 35, 341-346, (2009).

3. J. Bryant, G. Matthews and G. Walton, "Academic libraries and social and learning space", J. Librariansh. Inf. Sci., 41, 7-18, (2009).

4. S. Çankaya and S. Yilmazer, in Inter-Noise 2016, Institute of Noise Control Engineering, Hamburg, Germany, pp. 139-146.

5. D. Harrop and B. Turpin, "A study exploring learners' informal learning space behaviors, attitudes, and preferences", New Rev. Acad. Librariansh., 19, 58-77, (2013).

6. S. Yilmazer and V. Acun, "An indoor soundscape survey on the user's coping methods for noise annoyance, disturbance and loss of concentration in public study areas", AESOP 17, (2017).

7. V. Acun and S. Yilmazer, "Identification of individuals' emotional response to the indoor soundscape in public study areas via semantic differentiation", InterNoise 2017, (2017).

8. Acoustics-Soundscape-Part 1: Definition and conceptual framework, International Standard ISO 2014-1, International Organization for Standardization, (2014).

9. R.M. Schafer, The Soundscape: Our Sonic Environment and the Turning of the World, Destiny Books, Vermont, (1977).

10. D.A. Hall, A. Irwin, M. Edmondson-Jones, S. Phillips and J.E.W. Poxon, "An exploratory evaluation of perceptual, psychoacoustic and acoustical properties of urban soundscapes", Appl. Acoust., 74, 248-254, (2013).

11. A.L. Brown, "Advancing the concepts of soundscapes and soundscape planning", Proc. Acoust., 2011 1-9, (2011).

12. A.L. Brown, J. Kang and T. Gjestland, "Towards standardization in soundscape preference assessment", Appl. Acoust., 72 , 387-392, (2011).

13. W.J. Davies, M.D. Adams, N.S. Bruce, R. Cain, A. Carlyle, P. Cusack, D.A. Hall, K.I. Hume, A. Irwin, P. Jennings, M. Marselle, C.J. Plack and J. Poxon, "Perception of soundscapes: An interdisciplinary approach", Appl. Acoust., 74, 224-231, (2013).

14. V. Acun and S. Yilmazer, "Investigating the effect of indoor soundscaping towards employee's speech privacy", Euronoise 2015, 2461-2466, (2015).
15. J. Mackrill, P. Jennings and R. Cain, "Exploring positive hospital ward soundscape interventions", Appl. Ergon., 45, 1454-1460, (2014).

16. F. Aletta, J. Kang and Ö. Axelsson, "Soundscape descriptors and a conceptual framework for developing predictive soundscape models", Landsc. Urban Plan., 149, 65-74, (2016).

17. Z. Bora and S. Yilmazer, "Investigating the space recognition and soundmarks in open, semi-open and enclosed spaces via semantic ratings", AESOP 15, (2015).

18. "European Parliament and the Council Directive 2002/49/EC", (2002).

19. M. Yang and J. Kang, "Psychoacoustical evaluation of natural and urban sounds in soundscapes", J. Acoust. Soc. Am., 134, 840-851, (2013).

20. K. Vogiatzis and N. Remy, "From environmental noise abatement to soundscape creation through strategic noise mapping in medium urban agglomerations in South Europe", Sci. Total Environ., 482-483, 420-431, (2014).

21. A.J. Torija, D.P. Ruiz and A.F. Ramos-Ridao, "Application of a methodology for categorizing and differentiating urban soundscapes using acoustical descriptors and semantic-differential attributes", J. Acoust. Soc. Am., 134, 791-802, (2013).

22. R. Cain, P. Jennings and J. Poxon, "The development and application of the emotional dimensions of a soundscape", Appl. Acoust., 74, 232-239, (2013).

23. K. Kawai, T. Kojima, K. Hirate and M. Yasuoka, "Personal evaluation structure of environmental sounds: Experiments of subjective evaluation using subjects' own terms", J. Sound Vib., 277, 523-533, (2004).

24. A.S. Sudarsono, Y.W. Lam and W.J. Davies, "The effect of sound level on perception of reproduced soundscapes", Appl. Acoust., 110, 53-60, (2016).

25. F. Liu and J. Kang, "A grounded theory approach to the subjective understanding of urban soundscape in Sheffield", Cities, 50, 28-39, (2016).

26. X. Chen and J. Kang, "Acoustic comfort in large dining spaces", Appl. Acoust., 115, 166-172, (2017).

27. C.J. Yu and J. Kang, "Environmental impact of acoustic materials in residential buildings", Build. Environ., 44, 2166-2175, (2009).

28. G. Watts, A. Khan and R. Pheasant, "Influence of soundscape and interior design on anxiety and perceived tranquillity of patients in a healthcare setting", Appl. Acoust., 104, 135-141, (2016).

29. J. Mackrill, R. Cain and P. Jennings, "Experiencing the hospital ward soundscape: Towards a model", J. Environ. Psychol., 36, $1-8,(2013)$.

30. V. Acun and S. Yilmazer, "A grounded theory approach to investigate the perceived soundscape of open-plan offices", Appl. Acoust., 131, 28-37, (2018).

31. J. Kang and M. Zhang, "Semantic differential analysis of the soundscape in urban open public spaces", Build. Environ., 45, 150-157, (2010).

32. S. Boslaugh and P.A. Watters, Statistics in a Nutshell: A Desktop Quick Reference, 1st ed. O'Reilly, Sebastopol, (2008).

33. G. Argyrous, Statistics for Research with a Guide to SPSS, 3rd ed., Sage Publications, (2011).

34. M. Pierrette, E. Parizet, P. Chevret and J. Chatillon, 1, (2014).

35. C.D. Dziuban and E.C. Shirkey, "When is a correlation matrix appropriate for factor analysis? Some decision rules", Psychol. Bull., 81, 358-361, (1974).

36. J. Kang, F. Aletta, T.T. Gjestland, L.A. Brown, D. Botteldooren, B. Schulte-fortkamp, P. Lercher, I. Van Kamp, K. Genuit, J. Luis, B. Coelho, L. Maffei and L. Lavia, "Ten questions on the soundscapes of the built environment", Build. Environ., 108, 284-294, (2016).

37. F. Aletta, J. Kang, A. Astolfi and S. Fuda, "Differences in soundscape appreciation of walking sounds from different footpath materials in urban parks", Sustain. Cities Soc., 27, (2016). 
Copyright of Noise Control Engineering Journal is the property of Institute of Noise Control Engineering of the USA and its content may not be copied or emailed to multiple sites or posted to a listserv without the copyright holder's express written permission. However, users may print, download, or email articles for individual use. 